\title{
One module, different levels of merge: AN(N) compounds in Dutch
}

\author{
Marijke De Belder \& Marjo van Koppen \\ HUBrussel / CRISSP / FWO \& Utrecht University/UiL-OTS/NWO \\ marijke.debelder@hubrussel.be \& j.m.vankoppen@uu.nl
}

\begin{abstract}
In this article we provide empirical evidence against a Lexicalist view on morphology (Chomsky 1970, Lapointe 1980, DiSciullo \& Williams 1987 amongst many others). More specifically, we distinguish between three types of ANN compounds in Dutch. We show that the structural properties of these types do not show a one-to-one mapping with lexical properties, such as having a listed or even idiomatic meaning. On the basis of this, we argue that conclusions on the structure of certain morphologically complex word-forms should be based on structural properties and not on lexical properties such as idiomaticity or being lexicalized (pace Ackema \& Neeleman 2004 on Dutch ANN compounds). We further argue that there are no empirical grounds to postulate a separate morphological module. All ANN compounds in Dutch are built in syntax. Structural differences follow from the level of merge: what we traditionally call morphology is syntax below the functional domain.
\end{abstract}

Keywords: phrasal compounding, Dutch, listedness, Lexical Integrity Hypothesis, roots

\section{Introduction}

In this article we distinguish between three types of $\mathrm{AN}(\mathrm{N})$ compounds in Dutch, which we will refer to as lexicalized compounds, lexicalized phrases and productive compounds. Examples are given in 1)-3)

1) lexicalized compounds
a. hoog-bouw(-architectuur)
b. vol-bloed(-paard)
high-building(-architecture)
full-blood(-horse)
'high rise (architecture)'
'thoroughbred (horse)' 
a. rode-kool(-recept)

red-cabbage(-recipe)

'recipe for red cabbage' b. hoge-school(-student)

high-school(-student)

'college student'

3) productive ANN compounds
a. kale-katten-adoptie
b. gezonde-groenten-verkoper
hairless-cat-adoption
healthy-vegetables-seller
'adoption of hairless cats'
'seller of healthy vegetables'

The first two types contain listed or lexicalized material, the third type, on the other hand, is fully transparent and productive. Given that being lexicalized has been associated with being derived in a separate morphological module (DiSciullo \& Williams 1987 i.a.), one might suspect that they are built by such a module and therefore share structural properties in contrast with the third type. However, it will become clear that this is not borne out. Structurally, the second type is more similar to the third type, i.e. the productive compounds. The property of being lexicalized thus crosscuts structural characteristics. We will therefore argue against a separate morphological module and we will defend the thesis that all three types are derived in syntax by the operation Merge. However, the level of Merge may differ, giving rise to structural distinctions. More specifically, we claim that lexicalized compounds are derived via root merger, i.e. merger below category-specific functional projections, as in $0 \mathrm{a}$. The non-head of the first type is thus a compound consisting of roots which may be embedded in yet another compound, hence the third member is optional. Lexicalized phrases and productive compounds are derived from a partial NP, as in $0 \mathrm{~b}$. The non-head of the second and third type is thus a phrase which may be embedded in a compound, deriving an ANN compound. If it is not embedded in a compound, it is a syntactic phrase. 
4) a.

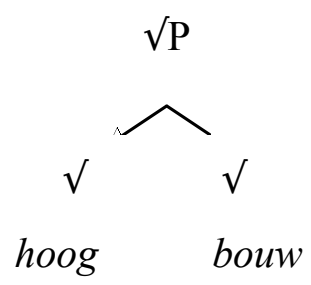

b.

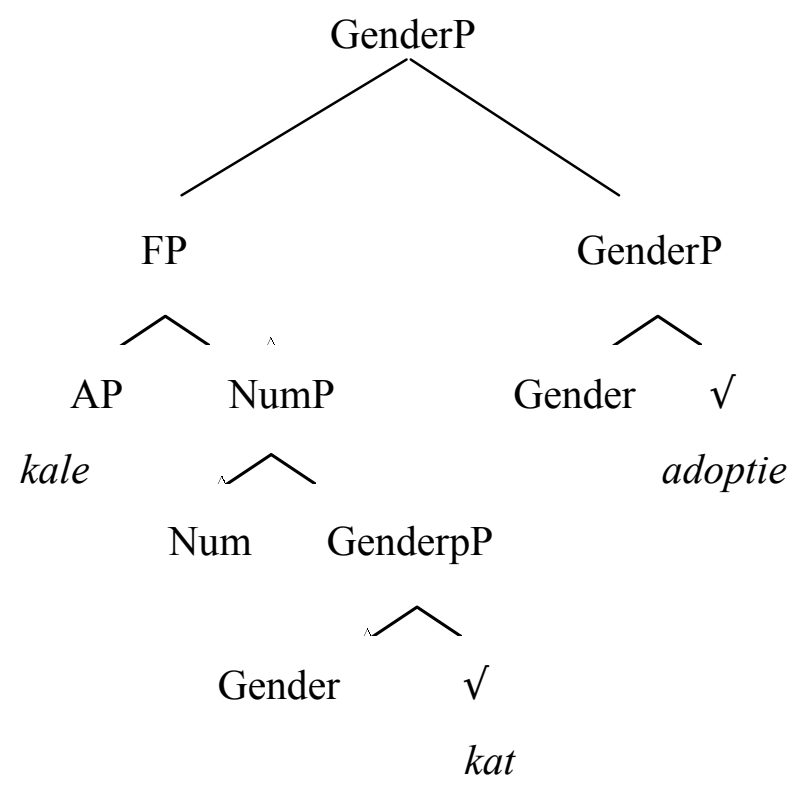

In sum, we will derive structural distinctions from the level of merge. Furthermore, we argue that the level of merge is independent of the property of being lexicalized. Although the first two types contain lexicalized material, only the first type involves root merger. Structural distinctions thus crosscut lexical ones.

To be entirely clear, in the remainder of this talk we will assume the following definition of being lexicalized:

5) Definition of lexicalized compounds or phrases

Lexicalized compounds or phrases are compounds and phrases that are recognized by the linguistic community as a fixed combination. As a consequence, they can most typically be found in a dictionnary.

Note that our definition of being lexicalized does not necessarily involve idiomaticity. Although lexicalized compounds or phrases may be idiomatic, this is not necessarily the case. For example, the compound in 6)a is lexicalized. It is 
attested in standard dictionaries of Dutch, such as Woordenboek der Nederlandsche Taal or Van Dale, which indicates that it is recognized as a listed word by the speech community. It is indeed a fixed combination, the adjective hoog 'high' cannot be replaced by another adjective, as is shown in the $b$ - and $c$ examples, even though this is possible in a DP, as in 7).

6) a. hoog-conjunctuur

high-economic climate

'boom'

b. * goed-conjunctuur

good-economic.climate

c. * sterk-conjunctuur

strong-economic.climate

7) een hoge/ sterke / goede conjunctuur

a high / strong / good economic.climate

'a high/strong/good economic climate'

Despite the fact that this compound is lexicalized, it is fully transparent. If a second language learner of Dutch knew the vocabulary items hoog 'high' and conjunctuur 'economic climate' independently, she will be able to deduce the meaning of the compound in 6). There is thus no reason to equate being lexicalized with idiomaticity. Note that idiomaticity of course implies being lexicalized. If an idiosyncratic meaning is associated with a fixed combination, the combination is necessarily the product of listedness. Idiomaticity is thus a stronger notion than being lexicalized. Keep in mind that in this article our claims are not about idiomaticity, but about the weaker notion of being lexicalized.

We will proceed as follows. In the following section we introduce the three types of $\mathrm{AN}(\mathrm{N})$ compounding in Dutch. We present five characteristics to distinguish between these types. In section 3 we provide an analysis for each type. Section 4 contains a discussion on a previous, contrasting proposal from Ackema and Neeleman 2004. Section 5 sums up and concludes. 


\section{Three subtypes of $A N(N)$ compounds in Dutch}

\subsection{Introduction}

In this section we will present five tests to distinguish between the three types of AN(N) compounds in Dutch. It will become clear that each type is defined by its own characteristics, which include the possibility of degree modification, being lexicalized, the presence or absence of inflection on the adjective, stress patterns and the possibility to contain a comparative or superlative form of the adjective. We then argue that $\mathrm{AN}(\mathrm{N})$ compounds containing a comparative or superlative never belong to the type of lexicalized compounds. They are invariably instances of either the second type, i.e. the lexicalized phrases, or of the third type, i.e. the productive ANN compounds, depending on their lexicalized status. Finally, we will present examples which seem to suggest there is a yet a fourth type of $A N(N)$ compounding. We will, argue, however, that looks may be deceiving and that this alleged fourth type fully patterns with the first type, i.e. the type of lexicalized compounds, of which it is a subtype. We conclude that Dutch has three types of $\mathrm{AN}(\mathrm{N})$ compounds.

\subsection{Five distinguishing characteristics}

\subsubsection{Lexicalization}

As the name suggests, lexicalized compounds and lexicalized phrases consist of lexicalized material. In the introduction we have defined being lexicalized as being recognized by the linguistic community as a fixed combination. As a result, such combinations can often be found in dictionaries. This is indeed the case for

\footnotetext{
${ }^{1}$ There is one other property that differentiates between these three types of compounds, namely a restriction on the gender specification of the most deeply embedded noun. Type 3 compounds (see ib), in contrast to type 1 compounds (see ia), resist neuter gender on the left most noun:

(i) a. hoog-seizoen-tarief

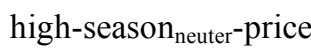

'price in the high season'
} 
the examples in 8) and 9), which can be found in Woordenboek der Nederlandsche Taal and Van Dale.

8) hoog-conjunctuur

high-economic climate

'boom'

9) rode-kool

red-cabbage

'red cabbage'

Productive ANN compounds belong to the domain of possible and not necessarily realized words. By definition, they are not listed or lexicalized. It should therefore not come as a surprise that 10), which was made up by the authors of this article, is not a lemma in any dictionary.

10) gezonde-groenten-verkoper

healthy-vegetables-seller

'seller of healthy vegetables'

Whether a word is attested in a dictionary is a first indication of listedness, but it may be subject to happenstance. It is therefore noteworthy that two other independent properties correlate with being lexicalized. Firstly, we have pointed out in the introduction that parts of a lexicalized expression cannot be replaced by synonyms. This was illustrated for hoogconjunctuur 'boom'. The relevant example is repeated below.

* goed-/sterk-conjunctuur good-/strong-economic.climate

In lexicalized phrases substitution by a synonym is penalized by a loss of the lexicalized meaning. The compounds in 12), for example, do not refer to a red cabbage. 
12) bordeaux- / scharlaken- / purper-kool burgundy- / scarlet-/ purple- cabbage 'cabbage which happens to be burgundy / scarlet red / purple of color'

A similar substitution is harmless, though, for productive ANN compounds. Given that their meaning is not lexicalized, no lexicalized meaning can be lost. The compositional meaning is thus retained if a synonym of the adjective is used, as 13) illustrates.

13) heilzame-groenten-verkoper

wholesome-vegetables-seller

'seller of wholesome vegetables'

In sum, lexicalized combinations do not allow a substitution of its parts by a synonym, whereas non-lexicalized productive compounds do allow such a replacement.

A second property which correlates with being lexicalized is the possibility of a meaningful stacking of the adjective or its antonym. In lexicalized compounds and phrases such a stacking is interpretable. This can be seen in the examples below. The $a$-examples show that the same adjective can be stacked, the $b$-examples show a similar effect with the adjective's antonym.

14) a. Peking heeft hoge hoog-bouw.

Bejing has high high-rise

'Bejing has high high-rise'.

b. De Amsterdamse Zuidas heeft lage hoog-bouw.

The Amsterdam South.axis has lage high-rise

'The Amsterdam South Axis has low high-rise'. 
15) a. Een lage $\mathrm{pH}$-waarde geeft rode rode-kool.

a low $\mathrm{pH}$-value yields red red-cabbage

'A low pH-value yields red red cabbage'.

b. Een high $\mathrm{pH}$-waarde geeft blauwe rode-kool.

a high $\mathrm{pH}$-value yields blue red-cabbage

'A high pH-value yields blue red cabbage'.

A comparable combination of adjectives leads to sheer nonsense in productive ANN compounds, which is marked by means of a hashmark.

16) a. \# gezonde-gezonde-groenten-verkoper

healthy-healthy-vegetables-seller

b. \# ongezonde-gezonde-groenten-verkoper

unhealthy-healthy-vegetables-seller

To conclude, in this subsection we have emphasized on a lexical distinction between lexicalized compounds and lexicalized phrases on the one hand and productive ANN compounds on the other. The first two types are lexicalized, i.e. they are recognized by the speaker as a fixed combination. As a result, it is not possible to substitute their parts by synonyms. However, it is possible to stack the adjective or its antonym in a meaningful way. The third type differs in this respect. It does not contain fixed combinations of vocabulary items. Consequently, it tolerates the substitution of its parts by synonyms. In contrast, a stacking of the adjective with the same adjective or its antonym leads to jabberwocky.

\subsubsection{Degree modification}

In lexicalized compounds the adjective cannot be modified by a degree modifier. It is thereby irrelevant whether the adverb of degree is understood as embedded within the compound or as a modifier of the entire compound. This is illustrated in 17). 
17) a. * [erg-hoog]-conjunctuur very-high-economic.climate

b. * erg [hoog-conjunctuur] very high-economic.climate

Similarly, lexicalized phrases cannot contain a degree modifier either, as shown in 18).

18)

$$
\begin{aligned}
& * \text { erg-rode-kool-recept } \\
& \text { very-red-cabbage-recepy }
\end{aligned}
$$

This restriction seems to be connected to the fact that the AN phrase contained within the compound is lexicalized. If one combines a degree modifier with the lexicalized phrase itself, the lexicalized meaning is lost and only a productive, ad hoc meaning can be assigned to the phrase.

19) een erg rode kool

a very red cabbage

'a cabbage which happens to be very red'

In contrast, productive ANN compounds containing a degree modifier are grammatical, as can be deduced from 20).

20) erg-gezonde-groenten-verkoper

very-healthy-vegetables-seller

'seller of very healthy vegetables'

In sum, lexicalized compounds and lexicalized phrases cannot contain an adverbial degree modifier, whereas productive ANN compounds do tolerate such a modifier.

\subsubsection{Inflection on the adjective}

In this section we will discuss whether the adjective which is contained in the $\mathrm{AN}(\mathrm{N})$-compound bears adjectival inflection. It will become clear that this is not 
the case for lexicalized compounds, whereas adjectival inflection is attested in lexicalized phrases and productive ANN compounds.

Lexicalized compounds do not contain adjectival inflection. This becomes clear when we compare the compound in 21)a with the indefinite and definite DPs in 22). Both DPs show a schwa ending on the adjective which realizes inflection. Such a schwa is obligatorily absent in the compound, as the $b$-example in 21) illustrates.

21) a. hoog-conjunctuur

high-economic.climate

'boom'
b. * hoog-e-conjunctuur high-INFL-economic.climate

22) a. een hoog-e conjunctuur

a high-INFL economic.climate 'a strong economic climate'

b. de hoog-e conjunctuur the high-INFL economic.climate 'the strong economic climate'

In this respect they differ from lexicalized phrases or productive ANN compounds which do contain inflection on the adjective. Let us first consider lexicalized phrases. As can be seen in 23), the adjective is marked with an inflectional ending, on a par with the adjective in the DPs in 24).

23) rood-e-kool

red-INFL-cabbage

'red cabbage' 
24) a. een rood-e kool

a red-INFL cabbage

'a cabbage which happens to be red'

b. de rood-e kool

the red-INFL cabbage

'the cabbage which happens to be red'

Adjectival inflection is attested in productive ANN compounds as well as can be deduced from a comparison between the compound in 25) and the DPs in 26).

25) gezond-e-groenten-verkoper

healthy-INFL-vegetables-seller

'seller of healthy vegetables'

26) a. gezond-e-groenten

healthy-INFL-vegetables

'healthy vegetables'

b. de gezonde groenten

the healthy-INFL vegetables

'the healthy vegetables'

In sum, adjectival inflection differentiates between lexicalized compounds on the one hand and lexicalized phrases and productive ANN compounds on the other hand. While lexicalized compounds lack adjectival inflection, it is attested in the other two types.

\subsubsection{Stress}

DP stress differs from compound stress in Dutch. DPs bear stress on the noun, as in 27), compounds bear stress on the leftmost part, as in 28). Small caps indicate stress. 
27) een slimme VROUW

a smart woman

'a smart woman'

28) een TONG-Zoen

a tongue-kiss

'a French kiss'

The question is now whether ANN compounds bear DP stress or compound stress. Lexicalized compounds typically get compound stress. This is shown in 29).

29) a. HOOG-bouw(-architect)

high-building(-archictect)

'high rise architect'

b. ZOET-hout-verkoper

sweet-wood(-seller)

'(seller of) liquorice'

c. VOL-bloed(-kwekerij)

full-blood(-farm)

'farm producing thorough-bred animals'

In the examples above stress is assigned to the leftmost part, clearly indicating these compounds bear compound stress. Admittedly, though, some minor idiolectal variation is attested for these compounds (see Haeseryn et al. 1997). For example, both 30)a and 30)b are attested.

30) a. KLEIN-geld(-portemonnee)

small-money(-purse)

'(purse for) coins' 
b. klein-GELD(-portemonnee)

small-money(-purse)

'(purse for) coins'

Stress patterns may thus vary marginally. Nevertheless, it is clear that lexicalized compounds most often take regular compounds stress.

Lexicalized phrases are assigned DP stress, as in the examples below. The lefthand AN phrase which is embedded in the compound is assigned stress as if it were an independent DP.

31) a. rode-KOOL(-recept)

red-cabbage(-recepy)

'(recepy for) red cabbage'

b. blinde-VINK(-recept)

blind-finch(-recepy)

'(recepy for) beef olives'

c. dikke-DARM(-ontsteking)

thick-intestine(-inflammation)

'(inflammation of the) large intestine'

Again, one may find some exceptional idiolectal variation in this domain. For example, 32)a and 32)b are both attested.

32) a. hoge-SCHOOL(-student)

high-school(-student)

'college (student)'

b. HOGE-school(-student)

high-school(-student)

'college (student)' 
In spite of such marginal counter-examples, it is still fair to state that the regular stress pattern for lexicalized phrases is DP stress.

DP stress is also attested in productive ANN compounds, as shown in the examples below.

33) a. gezonde-GROENTEN-verkoper

healthy-vegetables-seller

'seller of healthy vegetables'

b. kale-KATTEN-adoptie

hairless-cats-adoption

'adoption of hairless cats'

c. slimme-VROUWEN-vereniging

smart-women-association

'association for smart women'

To conclude, both compound stress and DP stress is attested amongst ANN compounds. Lexicalized compounds take compound stress, whereas lexicalized phrases and productive ANN compounds take DP stress.

\subsubsection{Comparatives and superlatives in ANN compounds}

ANN compounds in Dutch may contain the comparative or superlative form of an adjective. Examples are shown below.

34) a. hoger-huis-lid

higher-house-member

'member of the House of Lords'

b. hogere-machts-vergelijking

higher-power-equation

'equation of higher degree' 
The compounds containing a comparative or superlative may be lexicalized; they are recognized as fixed combinations and they loose their meaning if the adjective is replaced by means of a synonym, as shown in 35 ).

35) a. verheven-huis-lid

elevated-house-member

'member of an elevated house'

b. verheven-machts-vergelijking

elevated-power-equation

'equation of an elevated degree'

However, non-lexicalized, newly formed examples are not excluded either. Examples 36)a and 36)b are neologisms.

36) a. veiligere-narcose-ontwikkeling

safer-anesthesia-development

'development of safer anesthesia'

b. oudste-dochter-verantwoordelijkheid

oldest-daughter-responsibility

'responsibility of the oldest daughter'?

Whether the example is lexicalized or not, we argue that the comparative or superlative contains adjectival inflection. Compare the compounds in 34) with the DPs in 37) and 38). 37) shows indefinite DPs, 38) shows definite DPs.

\footnotetext{
${ }^{2}$ Note that the leftmost noun in these examples with type 3 compounds cannot be neuter singular because of an additional independent restriction on this type of compounds, see footnote 1.There is one exception on this restriction that becomes important here: if the adjective cannot show inflection due to its morphological shape, like verheven 'elevated' in (35)a, neuter singular nouns (like huis 'house' in this example) are allowed to occur.
} 
37)

a. een hoger- $\varnothing$ huis NEUTER

a higher-INFL house

'a higher house'

b. een hoger-e vergelijking ${ }_{\text {СоммоN }}$

a higher-INFLequation

'a higher equation'

38) a. het NEUTER $_{\text {hoger-e }}$ huis $_{\text {NEUTER }}$

the higher-INFL house

'the higher house'

b. de Соммом $_{\text {coger-e vergelijking }}$ соммоN

the higher-INFL equation

'the higher equation'

The adjectives in the compounds in 34) select a null inflectional marking if the noun they agree with is marked for neuter gender, see 34)a, they take a schwa ending otherwise, see 34)b. As such, they pattern with the inflection paradigm of indefinite DPs, which selects a null morpheme if the noun is neuter and singular and a schwa in all other cases. We take this to mean that the adjectives in 34) show adjectival inflection.

The fact that ANN compounds containing a comparative or superlative take adjectival inflection, indicates that they never belong to the first type, i.e. the lexicalized compounds. They either belong to the second type, i.e. the lexicalized phrases, or to the third type, i.e. the productive ANN compounds. We therefore propose that the lexicalized examples are instances of lexicalized phrases, whereas the neologisms are examples of productive ANN compounds.

This property of containing a comparative or superlative, relates to the ability to have degree modification (see section 2.2.2), since the comparative morpheme is a degree modifier (see Kennedy 1997). This is indeed what we find for productive ANN compounds. However, it seems to suggest that the lexicalized ANN compounds with a comparative or superlative are wrongly classified as lexicalized phrases as we have suggested that lexicalized phrases do not select 
degree modifiers (see section 2.2.2). Recall, though, that the two lexicalized types, i.e. the lexicalized compounds and the lexicalized phrases, cannot select degree modifiers as they loose their idiomatic meaning if they do. The relevant examples are repeated in 39) and 40).

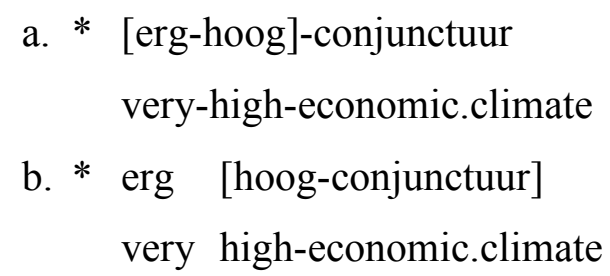

40)

$$
\begin{aligned}
& * \text { erg-rode-kool-recept } \\
& \text { very-red-cabbage-recepy }
\end{aligned}
$$

One may interpret these examples in two ways. One may conclude that they show that lexicalized types cannot select a degree modifier, as we have done above. Alternatively, one may conclude that these examples show that the degree modifier should be part of the lexicalized information. If we follow the second line of reasoning the ANN compounds containing a comparative may still pattern with the lexicalized types although they contain a degree modifier, since the degree morpheme is simply part of the listed information. We then predict that the examples loose their idiomatic meaning in the absence of a degree modifier. This prediction is is borne out, as is shown in 41).

41) a. hoog-huis-lid

high-house-member 'member of a high house'

b. hoge-machts-vergelijking high-power-equation 'equation of a high power'

We therefore modify the conclusion that lexicalized types cannot contain a degree modifier. More accurately stated, it is illicit to add or remove a degree modifier 
from a listed combination. The degree modifier thus suggests that these examples indeed may belong to the type of lexicalized phrases.

Finally, we predict that if these compounds are classified as productive ANN compounds or lexicalized phrases, they take DP stress. Now observe that Dutch DPs containing a comparative or superlative assign stress to the comparative, as in 42). Small caps indicate stress.

42) een SLIMMERE vrouw

a smarter woman

'a smarter woman'

43) de SLIMSTE vrouw

the smartest woman

'the smartest woman'

Recall that compound stress is assigned to the leftmost member of the compound, as in 44).

44) een TONG-Zoen

a tongue-kiss

'a French kiss'

The leftmost member of an ANN compound containing a comparative or superlative is of course the comparative or superlative adjective itself. As a consequence, we expect stress to fall on the comparative or superlative both in the case of DP stress and in the case of compound stress, rendering the test inconclusive. The comparative or superlative will be assigned stress according to either stress pattern. Unsurprisingly, it is indeed the comparative or superlative adjective which is assigned stress.

45) a. HOGER-huis-lid

higher-house-member

'member of the House of Lords' 
b. HOGERE-machts-vergelijking

higher-power-equation

'equation of higher degree'

Although the data thus fully behave as expected, the test is inconclusive for this type of ANN compounding. We conclude that the data are in any case compatible with the conclusion reached above, i.e. that ANN compounds containing a comparative or superlative are always examples of lexicalized phrases or productive ANN compounds and never of lexicalized compounds.

In short, in this section we have shown that ANN compounds containing a comparative or superlative pattern with lexicalized phrases and productive ANN compounds, depending on their status as being lexicalized or newly formed. They are never lexicalized compounds. The main indication which led to this conclusion is the fact that they take adjectival inflection. We have further pointed out that the degree modifier, i.e. the comparative or superlative morpheme, can be part of the lexicalized phrase. We have therefore modified the previous conclusion that lexicalized phrases cannot contain a degree modifier. What is rather at play is that one should not tinker with the stored information on the presence or absence of degree modifiers if one wants to retain the lexicalized meaning. Finally, we have pointed out that a test based on stress patterns is inconclusive in these cases as compounds stress and DP stress both happen to assign stress to the comparative or superlative adjective. We have concluded that at least the stress pattern does not contradict the conclusion we have reached above that ANN compounds containing a comparative or superlative are instances of lexicalized phrases or productive ANN compounds.

\subsubsection{A fourth type?}

There is yet another set of $\mathrm{AN}(\mathrm{N})$ compounds we have not discussed so far. These compounds typically contain an adjective which is followed by a schwa, as in 46). 
46) a. wit-e-brood

white-E-bread

'white bread'

c. plat-e-land

flat-E-land

'countryside'

e. blind-e-man

blind-E-man

'blindfolded player playing tag'

g. mal-e-molen

crazy-E-mill

'carousel' b. zoet-e-melk

sweet-E-milk

'plain milk'

d. vast-e-land

fixed-E-land

'mainland'

f. wild-e-bras

wild-E-brute

'tear-away'

h. mal-e-praat

crazy-E-talk

'drivel'

${ }^{3}$ Zoetemelk is the antonym of buttermilk. 
i. dol-e-praat

mad-E-talk

'drivel'

k. oud-e-jaar

old-E-year

'New Year's Eve' j. hard-e-bol

tough-E-ball

stubborn person'

1. wild-e-man

wild-E-man

'tear-away'

In this section we will argue that these compounds are a subtype of the first type, i.e. of the lexicalized compounds. We will therefore refer to them as lexicalized compounds with an intervening schwa. We thus expect them to disallow degree modification, to be lexicalized, to lack adjectival inflection and to be assigned compound stress. These expectations are borne out.

First consider degree modification. Example 47) shows that this type of compounding indeed looses its specific meaning when a degree modifier is added.

$$
\begin{aligned}
& \text { een erg wilde-man } \\
& \text { a very wild man } \\
& \text { 'a very wild man' } \\
& \text { * 'a terrible tear-away' }
\end{aligned}
$$

From the fact that most examples in 46) are clearly idiomatic one can deduce that they are lexicalized. After all, idiomaticity is a stronger notion than being lexicalized. If a compound is idiomatic this implies that the speech community attaches a non-compositional meaning to a fixed combination. It follows that the combination is indeed fixed, i.e. lexicalized.

We further predict that these compounds lack adjectival inflection. This is indeed the case, although they contain a schwa which at first sight could be mistaken for adjectival inflection. We have seen in section 2.2.6 that if the modified noun in a compound is a neuter noun, adjectival inflection is marked by means of a null morpheme, the schwa being restricted to common nouns. If the schwa truly were adjectival inflection, we expect it to be selected uniquely by compounds with a common noun. However, it co-occurs with neuter nouns as well, as can be deduced from the examples below. The examples in 48) show that 
the nouns brood 'bread' and land 'land' are indeed neuter. The examples in 49) show that the gender of these nouns does not affect the presence of the intervening schwa.

$\begin{array}{ll}\text { a. } \text { het }_{\text {NEUTER }} \text { brood }_{\text {NEUTER }} & \text { b. het } \\ \text { NEUTER } & \text { land }_{\text {NEUTER }} \\ \text { the bread } & \text { the land } \\ \text { 'the bread' } & \text { 'the land' }\end{array}$

49) a. wit-e-brood

b. plat-e-land

white-E-bread

flat-E-land

'white bread'

'country-side'

From the fact that the intervening schwa is not blocked by neuter nouns, we conclude it is not adjectival inflection. One may then wonder what the status of the schwa is. We conjecture it is there for phonological reasons. Considering the examples in 46) it is noticeable that the adjectives invariably end in a dental or a lateral consonant. Given the fact that one can attest such a phonological pattern, it is not unreasonable to assume the phonological context triggers the schwa, albeit for reasons we fail to understand. This hypothesis is further supported by the contrasting pair in 50).

50)
a. oud-e-jaar
b. nieuw-(*e)-jaar
old-E-year
new-year
'New Year's Eve'
'New Year'

There is no obvious reason to expect a structural difference between 50)a and 50)b. Yet, 50)a contains a schwa, whereas 50)b does not. This patterns with a phonological distinction; 50)a ends in a dental, whereas 50)b does not. In short, we conclude that the intervening schwa is triggered phonologically. It is not a realization of adjectival inflection.

Finally, we expect these examples to show compound stress. This expectation is indeed borne out, as is illustrated in 51). 
51) a. WIT-e-brood

white-E-bread

'whitebread' b. ZOET-e-melk

sweet-E-milk

'plain milk'

We have seen in section 2.2.4 that some examples of lexicalized compounds may show a deviating stress pattern. Admittedly, this is also the case for the examples under discussion. Both 52)a and 52)b are attested.

52)
a. OUD-e-jaar
old-E-year
'New Year's Eve'
b. oud-e-JAAR
old-E-year
'New Year's Eve'

In short, the stress pattern of these compounds is fully compatible with the hypothesis that they are a subtype of lexicalized compounds. To summarize, from the fact that these compounds show all the characteristics of lexicalized compounds, we propose they are a subtype thereof. The intervening schwa is triggered by the phonological context.

\subsection{Conclusion}

We have presented four tests to differentiate between three types of ANN compounds in Dutch. These tests involve distinctions in being lexicalized, in the possibility to host an adverbial degree modifier, in allowing adjectival inflection, in stress patterns and in allowing a comparative or a superlative. Finally, we have shown that lexicalized compounds may contain an intervening schwa which is triggered by the phonological make-up of the adjective. The results of this section are summarized in the table in 53). 


\begin{tabular}{|l|l|c|c|}
\hline & $\begin{array}{l}\text { Lexicalized } \\
\text { compounds with or } \\
\text { without an } \\
\text { intervening schwa }\end{array}$ & $\begin{array}{l}\text { Lexicalized phrases } \\
\text { ANN } \\
\text { compounds }\end{array}$ \\
\hline $\begin{array}{l}\text { lexicalized } \\
\text { modification }\end{array}$ & $\checkmark$ & $\times$ & x \\
\hline adjectival inflection & $x$ & $\checkmark$ & $\checkmark$ \\
\hline DP stress & $x$ & $\checkmark$ & $\checkmark$ \\
\hline comparative or superlative & $x$ & $\checkmark$ & $\checkmark$ \\
\hline
\end{tabular}

Overview of ANN compounds in Dutch

A closer look at this table reveals that lexicalized compounds and lexical phrases pattern alike when it comes to lexical properties, such as being lexicalized, and that lexical phrases and productive ANN compounds are similar structurally. Lexical properties thus cross cut structural ones. In the next section we develop this observation in full detail.

\section{Analysis: Root merger vs. NP merger}

\subsection{Introduction}

In this section we argue that lexicalized compounds involve bare root merger, whereas the left-hand part of lexicalized compounds and productive ANN compounds is truly phrasal, i.e. it contains a partial NP. We first discuss lexicalized compounds and then we focus on productive ANN compounds. Lexicalized phrases are analyzed last. 


\subsection{Root merger of lexicalized compounds}

In this section we will present an analysis of lexicalized compounds, as in 54).

a. hoog-bouw(-architectuur)

high-building(-architecture)

'high rise (architecture)'

b. zoet-hout(-verkoper)

sweet-wood-seller

'(seller of) liquorice'

c. klein-kunst(-theater)

small-art-theatre

'cabaret (theatre)'

We adopt the view that the core of a lexical projection is a categoriless root (Halle and Marantz 1993, Harley and Noyer 1999, Borer 2005). We propose that lexicalized compounds involve the merger of bare roots, as in 55). ${ }^{4}$

55)

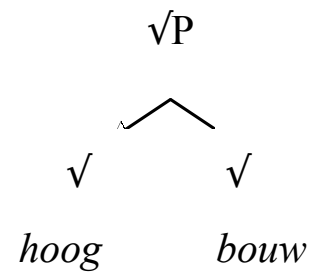

In the structure in 55) the root which we referred to as an adjective is not an adjective in the technical sense of the word. It is but a bare, uncategorial root. The following empirical properties follow from this structure. It is expected that lexicalized compounds do not take adjectival inflection as there is no adjectival structure present in the tree. In the same vein, degree modifiers cannot merge as there is no AP to host them.

\footnotetext{
${ }^{4}$ The structure is simplified for ease of exposition. A fully developed derivation of compounds would take us too far afield. We would like to refer the reader to Borer (2009, to appear) for a detailed derivation of compounds in a root-based framework.
} 
Given the Coordination of Likes Constraint (Chomsky 1959) which states that coordination is only possible if the conjuncts belong to the same category ${ }^{5}$, it is expected that APs cannot be stacked on top of the root, as APs and roots are of different categories. This expectation is borne out, as is illustrated below. 56) shows an AP, 57) shows a lexicalized compound, 60) shows the restriction on coordinating APs and the alleged adjective of the lexicalized compound.

56) bijzonder-e kunst

exceptional-INFL art

Intended: 'exceptional art'

57) klein-kunst

small-art

'cabaret'

58) * bijzondere- en klein-kunst

exceptional- and small-art

Intended: 'exceptional cabaret'

In contrast, we predict that the alleged adjective can be coordinated with other roots, even if they are associated with different categories. After all, structurally they are all roots and thus are of the same category (see De Belder 2013). This is indeed the case. 59) shows a lexicalized compound of which the root might be taken for a noun. The licit coordination can be seen in 60 ).

59) a. straat-kunst

street-art

'street art'

60) a. straat- en klein-kunst

street- and small-art

'street art and cabaret'

\footnotetext{
${ }^{5}$ See Sag et al. (1985) for a more detailed view.
} 
In sum, the analysis presented in 55) is fully compatible with their behavior under coordination.

Note that the structure in 55) is derived in syntax and not in a separate morphological module. The reader may wonder how it follows that lexicalized compounds are invariably lexicalized. Although they are productive, they cannot be formed on the spot (Ackema \& Neeleman 2004).
a. * fris-wind fresh-wind
b. * blauw-oog blue-eye

Despite the productivity, the licitness of the newly formed compound depends on listedness. The speech community has to recognize the new compound as a (newly) listed combination. We will address this issue in what follows.

We adopt the view that bare roots are categorized by means of the functional projections which merge on top of it. For example, if number marking and a Dlayer merge above a root, the root becomes nominal, if tense merges above a root, it will be verbal. Categorization is thus not done by categorial heads or lexical specifications (Borer 2005, 2013, De Belder 2011). As a consequence, adjectives are defined by designated functional projections as well, which we assume to be projections of degree (Corver 1990, 1997, Kennedy 1999). Technically, an adjective is thus not a particular lexical projection. It is rather defined as a relation between a predicate as expressed by a root and a degree established by means of functional projections. Roots thus depend on projections of degree to function as adjectives. To compute the meaning of an adjective in a compositional fashion, LF thus depends on degree projections as well. Now observe that bare roots as in 55) lack such functional projections. Hence, an adjectival meaning cannot be computed compositionally. The only possible meaning for the structure in 55) is therefore a stored one, which is not necessarily idiomatic (see section 1). As such, we derive the connection between being lexicalized and root merger.

To summarize, we have analyzed lexical compounds as instances of root merger. We have shown that their empirical properties can be derived from this structure. For example, it is expected that they resist adjectival properties such as 
degree modification and adjectival inflection. It further follows that the root can be licitly coordinated with other roots, but not with adjectives. Finally, being lexicalized results immediately from the defective structure.

\subsection{NP merger of productive ANN compounds}

We propose that the non-head of a productive ANN compound, as in 62), is a partial $\mathrm{NP}^{6}$, as in 63). Syntactically, it is thus a phrase.

62) a. kale-katten-adoptie hairless-cat-adoption 'adoption of hairless cats' b. gezonde-groenten-verkoper healthy-vegetables-seller 'seller of healthy vegetables'

63)

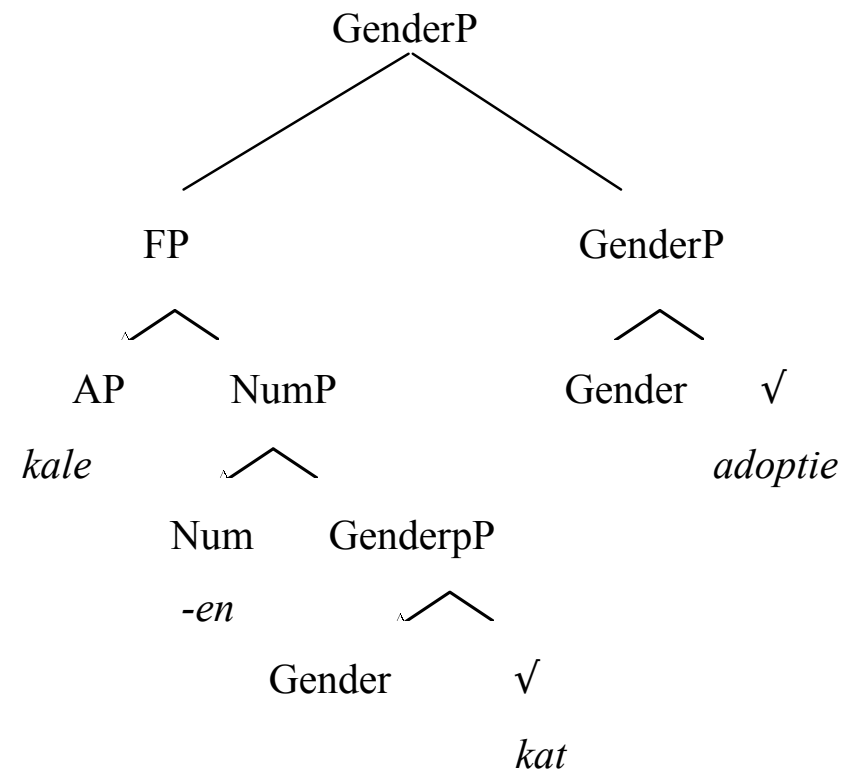

The presence of an AP-layer in 63) captures the fact that productive ANN compounds may contain adjectival features. We have pointed out that these compounds allow degree modifiers and comparative and superlative morphemes

\footnotetext{
${ }^{6}$ The non-head of a compound can never include a D-layer due to the fact that the non-head cannot be referential (see Harley 2009, Borer 2009). One can find examples with a possessive pronoun, though, such as Onzelievevrouwekerk (our-sweet-lady-church) 'Church of Our Lady', in which case the possessive pronoun is part of a proper name. The fact that it does not function as a proper possessive pronoun in these examples can be deduced from the fact that it is fixed, hence it cannot be replaced as in *jullielievevrouwekerk (your-sweet-lady-church).
} 
and that they contain adjectival inflection. These properties follow immediately from the structure. After all, it is expected that an AP phrase can contain material which is typically associated with such a phrase. Furthermore, we see no reason why this structure should not be productive; NPs can be built as you like. Finally, note that one predicts that the adjective can be coordinated with another one or that several adjectives can be stacked. This is borne out. 64) shows an example of coordinated adjectives, 65) illustrates stacking.

64) kale- en zieke-katten-adoptie

hairless-and ill-cats-adoption

'adoption of hairless and ill cats'

65) kale-zieke-katten-adoptie

hairless-ill-cats-adoption

'adoption of hairless, ill cats'

In sum, in order to capture the fact that the adjective in productive ANN compounds shows the syntactic behavior of a full-blown adjective, we propose to analyze the left-hand AN phrase of the compound as a partial NP with a complete AP layer.

\subsection{NP merger of lexicalized phrases within compounds}

Lexicalized phrases which are embedded in a compound share structural properties with productive ANN compounds. Both types contain adjectival inflection and both may contain a comparative or superlative form of the adjective. We therefore propose to analyze lexicalized phrases on a par with productive ANN compounds. In other words, lexicalized phrases within compounds are partial NPs as well, as in 66). 
66)

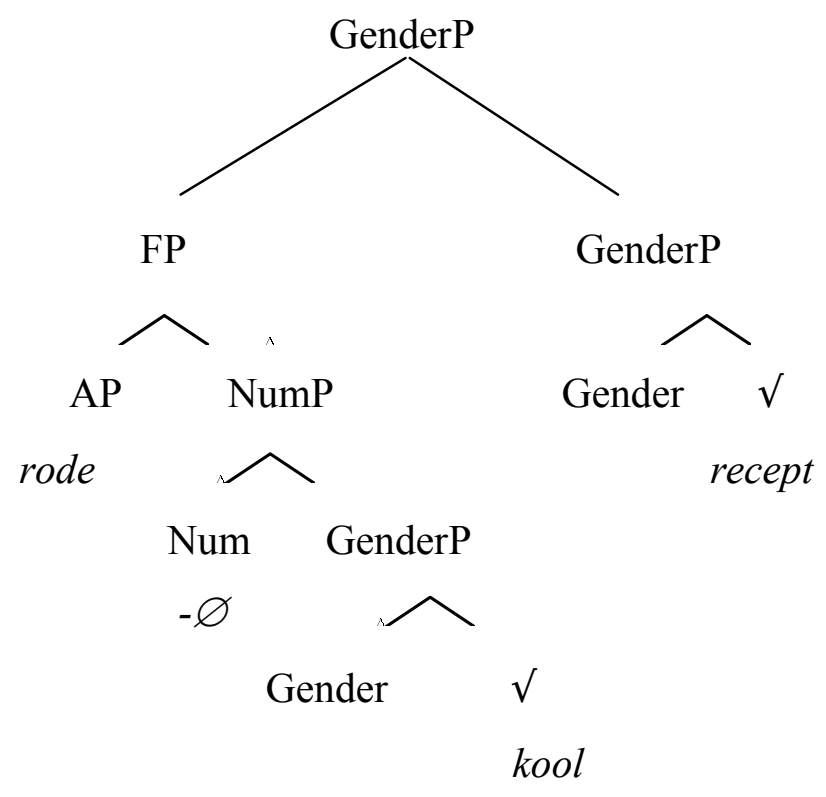

However, we have discussed a distinction between productive ANN compounds and lexicalized phrases. Whereas one can add a degree modifier to productive ANN compounds, this option is excluded for lexicalized phrases. Yet, we have argued that this difference does not stem from the fact that lexicalized phrases resist a degree modifier. After all, they may contain a comparative or superlative morpheme. What is relevant, though, is the fact that lexicalized phrases can only contain degree modification if it is part of the stored information. This distinction between productive ANN compounds and lexicalized phrases is thus not a structural distinction. It rather stems from the lexical property of being lexicalized.

A similar effect can be observed when considering the coordination of adjectives in lexicalized phrases. They do allow coordination with other adjectives, as expected. This is shown in 67).

67) a. groene-kool

green-cabbage

'green cabbage' 
b. rode-kool

red-cabbage

'red cabbage'

c. groene- en rode-kool

green- and red cabbage

'green and red cabbage'

In these examples, it is relevant that groen 'green' and rood 'red' are indeed both structurally adjectives. If one coordinates rood 'red' with another category, the coordination is illicit.

68) a. spits-kool

peak-cabbage

'conical cabbage'

b. rode-kool

red-cabbage

'red cabbage'

c. * spits- en rode-kool

peak-and red cabbage

As lexicalized phrases contain an AP-layer they thus can be coordinated with other adjectives and not with other categories, as expected. Yet, they cannot be coordinated with just any adjective, as is illustrated in 69).

69) a. lekkere kool

tasty cabbage

'tasty cabbage'

b. rode-kool

red-cabbage

'red cabbage' 


$$
\begin{gathered}
\text { c. }{ }^{*} \text { lekkere- en rode-kool } \\
\text { tasty- and red cabbage }
\end{gathered}
$$

We propose that the illicitness of 69)c is not due to a structural restriction, it rather goes back to a lexical restriction. Note that the DP in 69)a is fully compositional, it is not lexicalized. Now observe that although listed items can be coordinated, this is not necessarily the case for listed and non-listed items. 70) shows examples of listed imprecations.

70) a. Krijg de tyfus.

get the typhoid

(imprecation)

b. Krijg de tering

get the tuberculosis

(imprecation)

Although the imprecation may contain various names of diseases, not all diseases can be part of the idiom. 71), for example, is not a listed imprecation.

71) Krijg de griep.

get the flu

'Get the flu.'

* imprecation

One can licitly coordinate the names of the diseases as long as they are both listed as imprecations, as can be seen in 72). However, coordinating listed and nonlisted items is ungrammatical, as is shown in 73).

\footnotetext{
${ }^{7}$ This example is pragmatically odd as it is unlikely one would order someone to catch a disease. An interpretation as an imprecation is excluded.
} 
72) Krijg de tyfus en de tering.

get the typhoid and the tuberculosis

(imprecation)

73) * Krijg de tyfus en de griep. $^{8}$

get the typhoid and the flu

We propose to ascribe the ungrammaticality of 69)c to this phenomenon. One cannot coordinate listed and non-listed items, even though this should be possible structurally.

In sum, we propose that differences between productive ANN compounds and lexicalized phrases can be derived from the fact that productive ANN compounds are interpreted compositionally and the second type is stored, even though they are built by means of the same structure. Both types contain an AP-layer.

\subsection{Conclusion}

In this section we have proposed that the non-head of lexicalized compounds contains nothing but bare roots. As such, we can derive the fact that they disallow adjectival features, such as degree modifiers, comparatives and superlatives and inflection. Furthermore, it follows that they can be coordinated with other roots, but not with adjectives. The fact that lexicalized compounds are obligatorily listed follows from the absence of a functional structure. As LF depends on functional structure to interpret the predicate expressed by a root compositionally, the conceptual module necessarily depends on readily available stored information.

We proposed that the left-hand part of productive ANN compounds and lexicalized phrases is a partial NP containing an AP-layer. As such, it follows immediately that these types may contain adjectival features, such as inflection and degree modification and that they are assigned DP stress. We have argued that restrictions on lexicalized phrases follows from the lexical property of being listed, rather than from structural considerations.

More generally, we have observed that being lexicalized is not associated with one particular structure. Being lexicalized is a property which cross cuts structural

\footnotetext{
${ }^{8}$ The example is ungrammatical as an imprecation.
} 
properties. It therefore does not make sense to postulate a separate module in which lexicalized compounds are derived (pace Ackema and Neeleman 2004 on ANN compounding). We have argued that all compounds are built in syntax, yet the level of merge may differ. Some compounds contain roots, whereas others contain phrases.

\section{Conclusion}

In this article we have distinguished between three types of ANN compounds in Dutch, which we referred to as lexicalized compounds, lexicalized phrases and productive ANN compounds. We have shown that the structural properties of these types, wich we derived from the level of merge, cross cut the lexical property of being lexicalized. Given that structural properties do not show a oneto-one mapping with lexical properties, it is undesirable to postulate a separate module to derive lexicalized combinations. Alternatively, we proposed that all AN(N) compounds are merged in syntax. In short, we have presented empirical evidence against a Lexicalist view (Di Sciullo and Williams 1987) which associates listedness and idiomaticity with a separate module, viz. Morphology.

More specifically, we have shown that lexicalized compounds are fixed, listed combinations which do not allow any adjectival material, such as degree modification or adjectival inflection. They do not take DP stress either. We have argued that these properties result from the fact that they do not contain an adjective in a technical sense. What is recognized as an adjective is structurally but a bare, categoriless root. We have further derived the property of being lexicalized from this structure. Given that the root lacks adjectival functional projections, it cannot be interpreted as an adjective and LF fails to compute a compositional meaning. The structure depends on the availability of a stored denotation.

We have analyzed both compounds including lexicalized phrases and productive ANN compounds as compounds of which the non-head is a partial NP hosting an AP-layer. This structure captures the fact that the adjective in these compounds contain adjectival properties, such as inflection or degree modification and that the AN phrase receives DP stress. We have emphasized on the fact that restrictions on lexicalized phrases do not stem from structural distinctions, but 
from the mere fact that they are lexicalized. In sum, we have argued that conclusions on structure building in the domain of word-formation should not be based on lexical properties, such as being lexicalized.

\section{Acknowledgements}

We would like to thank the members of CRISSP (Dany Jaspers, Guido Vanden Wyngaerd, Jeroen van Craenenbroeck, Tanja Temmerman, Adrienn Jánosi and Koen Roelandt), Bettina van den Broek, Norbert Corver, Heidi Klockmann, Franca Wesseling, Nina Wiedenhoff and Gertjan Postma for comments and discussion. We would further like to thank the audience of BCGL 7. Marijke De Belder would gratefully like to acknowledge this research was made possible by a postdoctoral fellowship (Ambiguous words, application number $1285513 \mathrm{~N}$ ) from the Flemish Foundation for Science (Fonds voor Wetenschappelijk Onderzoek, $F W O$ ). Marjo van Koppen would gratefully like to acknowledge this research was made possible by NWO.

\section{References}

Ackema, P. \& A. Neeleman (2004) Beyond Morphology. Oxford: OUP.

Borer, Hagit (2005) In name only. Structuring Sense, Volume I. Oxford: OUP.

Borer H. (2009) Compounds: the view from Hebrew. In Lieber, R. \& P. Štekauer (eds.) The Oxford handbook of compounding. Oxford: Oxford University Press.

Borer, Hagit (2013) Taking Form. Structuring Sense, Volume III. Oxford: OUP.

Chomsky, Noam (1970) Remarks on Nominalization. In Jacobs, R. and P.

Rosenbaum (eds.) Readings in English Transformational Grammar. Waltham, MA: Ginn.

Corver, Norbert (1990) The syntax of left branch constructions. Doctoral dissertation, Tilburg University.

Corver, Norbert (1997) The internal syntax of the Dutch extended adjectival projection. NLLT 15, pp. 289-368.

De Belder, Marijke (2013) The root and nothing but the root: primary compounds in Dutch. Ms., HUBrussel.

De Belder, Marijke \& Marjo van Koppen (in preparation) Looking into ANN compounds in Dutch. Ms., HUBrussel \& Utrecht University. 
Di Sciullo, Anna Maria \& Edwin Williams (1987) On the definition of word. Cambridge, Mass.: MIT Press.

Harley, Heidi (2009) Compounding in DM. In Lieber, R. \& P. Štekauer (eds.) The Oxford handbook of compounding. Oxford: Oxford University Press.

Kennedy, Chris (1999) Projecting the adjective. NY: Garland Press.

Lapointe, Steven G. (1980) A Theory of Grammatical Agreement. Ph.D. diss., University of Massachusetts, Amherst. 